\title{
EVASÃO ESCOLAR: UM DESAFIO PARA A EDUCAÇÃO NA ATUALIDADE
}

\author{
Carmem Cleide Alves \\ Leila Aparecida Maciel de Lavor \\ Hérica Paiva Pereira
}

\begin{abstract}
Resumo
O objetivo deste artigo é apresentar a evasão escolar como resultado das práticas educativas que permeiam o processo de ensino aprendizagem, mas também os fatores internos e externos que conduzem a isso, ressaltando que ambas as partes envolvidas (aluno-professor) possuem compromissos neste processo. Cabe ressaltar que a responsabilidade do docente é ainda maior, dado à sua função, enquanto formador. No que se refere ao aluno, destacamos a deficiência cognitiva intelectual, bem como as questões sociais que alguns trazem para a escola. Quanto ao professor colocamos em questão a prática de alguns, ainda arraigados na perspectiva tradicional, o método de avaliação e sua capacidade de acolher a diversidade apresentada pelos discentes. Como proposta de mudança, apresentamos as práticas de letramentos como subsídio relevante na construção da metodologia a ser utilizada em sala de aula, já que essa envolve o aluno como um todo, ao considerar a sua cultura, valores, conhecimentos, crenças, etc. Portanto é uma proposta de mudança que requer um novo compromisso com a prática docente, propriamente dita. Para isso utilizamos uma pesquisa bibliográfica, através de uma abordagem qualitativa, por meio de um método dedutivo. Como proposta de atividade, apresentamos, no terceiro capítulo, um exercício, através do poema: "As borboletas" de Vinicius de Morais, a ser realizado com crianças que estão no nível silábico, com a intenção de desenvolver melhor este método através de uma prática de letramento. A pesquisa está fundamentada, principalmente, nas teorias de Kleiman (2016); Soares (1998) e Angelucci (2004), que nos permitiram chegar à conclusão de que é necessário repensarmos as práticas pedagógicas na educação, oferecida na atualidade.
\end{abstract}

Palavras chave: Evasão escolar; Práticas educativas; Letramento.

\section{TRUANCY: A CHALLENGE FOR EDUCATION TODAY}

\begin{abstract}
The aim of this paper is to present truancy as a result of educational practices that permeate the teaching and learning process, but also the internal and external factors that lead to this, nothingthat both parties (student - teacher) have commitments in this process. It is noteworthy that the teaching responsibility is even greater its role as a trainer. With regard to the student, we highlight the intellectual cognitive impairment, as well as the social issues that some bring to school. As for the teacher put in question the practice of some, still rooted in the traditional perspective, the evaluation method and its ability to embrace diversity presented by students. As proposed change, we present the literacies practices as relevant subsidy to build the methodology to be used in the classroom, since this involves the student as a whole, considering their culture, values, knowledge, beliefs, etc. So is a proposed change that reguires a new commitment to teaching practice itself. For this we use a literature search through a qualitative approach, through a deductive method. As activy proposal, presented in the third chapter, an exercise through the poem: "Butterflies" of Vinícius de Morais, to be held with children who are in the syllabic level, with the intention to further develpo this method through a practice literacy. The research is based mainly on the theories of Klaiman (2016), Soares (1998) and Angelucci (2004) which allowed us to reach the conclusion that it is necessary to rethink the pedagogical practices in education offeredtoday.
\end{abstract}

Keywords: Dodging school; Educational practice; Literacy. 


\section{INTRODUÇÃO}

A evasão escolar é um fenômeno bastante comum nas escolas brasileiras e tem como um dos fatores o fracasso das práticas educativas, vivenciadas diariamente por professores, que visam apenas a formação moral e intelectual dos seus alunos. Tal fenômeno ocorre de forma dissimulada, excluindo a todos aqueles que não se enquadram às exigências do sistema educacional. Isso se dá porque muitas vezes os alunos são submetidos a adentrarem num mundo cultural totalmente adverso ao seu, ou seja, a linguagem exercida pela escola, muitas vezes não condiz com o contexto social do aluno e muito menos com a bagagem cultural que este possui ao chegar nas Instituições.

Embora tenha ocorrido uma evolução educacional no Brasil nos últimos 30 anos, o contexto educacional, vigente, ainda enfrenta limitações dentro das novas tendências educacionais.

Outro aspecto importante é a avaliação, uma vez que é freqüente ser considerada somente como meio de aprovação ou reprovação, sendo neste caso um fator preponderante no sucesso ou insucesso dos alunos, que desta forma serão ou não bem sucedidos na vida escolar.

Existem também, aspectos externos e internos que favorecem ao fracasso escolar e que, estão vinculados aos papeis tanto do aluno como do professor. No caso dos alunos, destacamos aqui, certas carências, que nossos alunos apresentam, tanto na questão cognitiva intelectual como nas questões sociais que eles trazem para a escola. Quanto ao docente, o peso é maior, já que, além de ser o formador, compete a ele ser uma referência para seus alunos. No entanto, muitas vezes, percebemos que este compromisso falta, principalmente em se tratando de práticas defasadas, ainda utilizadas por muitos, como é o caso do método tradicional de ensino.

No que se refere à avaliação não é diferente, pois não existe uma preocupação em desenvolver o raciocínio lógico do aluno, mas sim de apresentar atividades com respostas evidentes, descartando a possibilidade de ampliar seus conhecimentos, possibilitando-lhe atuar como um sujeito ativo e participativo de sua aprendizagem. Enfim, questionamos também a postura de certos docentes descompromissados em acolher o discente na sua heterogeneidade.

Como objetivo, queremos apresentar a evasão escolar como resultado das práticas educativas que permeiam o processo de ensino aprendizagem. Para isso, a RPI Revista de Pesquisa Interdisciplinar, Cajazeiras, v. 1, n. 1, 70-78, jan/jul. de 2016. 
pesquisa está fundamentada, principalmente, nas propostas de KLEIMAN (2016); SOARES (1998) e GUIMARÃES (2014), que desenvolvem estudos acerca da evasão escolar e propostas de letramento nas práticas escolares. Enquanto que a metodologia utilizada é uma abordagem qualitativa através de uma pesquisa bibliográfica, por meio de um método dedutivo.

O trabalho consta de três capítulos, no qual a introdução é considerada o primeiro. No segundo apresentamos a temática da evasão escolar, considerando que essa é efeito de atitudes realizadas tanto por alunos como por professores. Enfim, no terceiro capítulo, apresentamos a prática do letramento como um modelo a ser utilizado hoje em nossas práticas pedagógicas.

\section{A EVASÃO ESCOLAR: UM DESAFIO HOJE}

Neste capítulo apresentaremos uma discussão acerca da evasão escolar como consequência de tudo o que concerne aos direitos e deveres dos sujeitos envolvidos no processo de ensino e aprendizagem. Para isso, trataremos de dois pontos que nos parece ser relevantes: o aluno no processo de evasão escolar e os efeitos negativos da prática docente. Esses temas nos parecem relevantes mediante a necessidade da Escola rever suas práticas e atuar como instituição formadora de cidadãos capazes de exercer sua cidadania plena.

\section{O aluno no processo de evasão escolar}

Existem diversos fatores geradores da evasão escolar, entre eles podemos destacar a questão do desenvolvimento cognitivo e intelectual do aluno. Para Angelucce e Kalmus (2004), o baixo nível de desenvolvimento intelectual do educando, pode leválo ao fracasso escolar, e o desenvolvimento ao qual nos propomos discutir, não está ligado à cultura a qual a criança pertence, ou seja, não podemos afirmar que uma criança da classe popular possui um grau de desenvolvimento intelectual inferior, baseada no meio cultural ao qual pertence, e que a criança que pertencente à classe dominante é superior por está inserida em uma cultura mais vasta.Também não estamos defendendo a meritocracia, onde as crianças são vistas com condições iguais de desenvolvimento, baseado na capacidade intelectiva, apenas, sem considerar os fatores externos. O meio social exerce uma forte influencia sobre o sujeito, no que se refere à 
aquisição de conhecimento e ao acesso e permanência na Escola. Não podemos minimizar a questão social, nem tampouco o contexto familiar ao qual pertence a criança. A inibição intelectual causada por dificuldades emocionais como: ansiedade, dificuldade de atenção, dependência, agressividade, entre outros que resulta em uma aprendizagem deficitária leva muitas vezes a retenção do aluno e logo a evasão. Outro fator importante que contribui significativamente para o sucesso e/ou insucesso escolar está ligado aos estímulos internos de cada indivíduo, é o que Guimaraes e Baruchoviten (2004) chamam por motivação intrínseca, que são os motivos interiores que o aluno tem para alcançar o sucesso escolar. Nessa perspectiva, o sujeito, mesmo estando diante das adversidades, encontra motivos para superar as dificuldades no processo de aprendizagem. A teoria da autodeterminação que está centrada no desenvolvimento da auto capacidade de aquisição do conhecimento por meio de forças interiores adquiridas ou necessidades psicológicas inatas que Guimaraes e Baruchovitcn (2004, p. 145) dividem em três necessidades, é o que o educando possui para que ocorra a aprendizagem. A primeira está voltada à autonomia que é a capacidade que o ser humano possui de se governar, a segunda é a competência, que para Rios (2011) é a capacidade que o ser humano possui de fazer bem aquilo que se sabe fazer. Trazendo para o campo educacional, na figura do educando é a realização de ações educacionais propostas e por fim a terceira necessidade que é o estabelecimento de vínculos, sendo essa ligada às práticas sociais, ou seja, é a necessidade que o educando possui de interagir socialmente, de criar vínculos afetivos e se relacionar com outros indivíduos. São essas necessidades que possibilitam ao aluno o reconhecimento das motivações extrínsecas que são os estímulos externos. Assim sendo, a auto-motivação permite que o aluno esteja na escola e se desempenhe na busca pelo conhecimento, permanência e sucesso escolar, uma vez que seu interesse provém de um desejo próprio e não por imposições e obrigações externas.

\section{Efeitos negativos da prática docente}

É impossível descrever com precisão as múltiplas causas da evasão Escolar no Brasil, no entanto, não podemos ignorar o papel que o professor exerce na formação do aluno, logo ele assume direto ou indiretamente, certa responsabilidade no sucesso ou insucesso escolar do educando. 
A educação, nestes últimos anos, tem passado por grandes modificações, graças ao empenho constante de muitos pesquisadores, de universidades diversas, que buscam incansavelmente novos caminhos para um ensino aprendizagem eficaz, capaz de formar o aluno na sua íntegra. No entanto existem, atualmente, profissionais docentes que ainda trabalham em uma perspectiva do modelo tradicional que, segundo Kleiman (2007) é uma aprendizagem que está limitada a desenvolver as habilidades individuais do discente, desconsiderando suas competências e conhecimentos que o faz capaz de desenvolver-se como um sujeito ativo e participativo de sua aprendizagem.

Esta realidade é ainda mais relevante no que diz respeito à avaliação, porque grande parte das práticas educativas, ainda utilizam métodos ultrapassados que desprezam o desenvolvimento cognitivo do aluno com tarefas mecânicas. Estas são meramente repetitivas, com o intuito do aluno reproduzir apenas o que está escrito no texto, não oferecendo a possibilidade de que ele seja crítico naquilo que lê e que interpreta e portanto, este tipo de atividade não avalia seus reais conhecimentos.

Na visão de Vasconsellos (2014) o sistema de avaliação tem sido usado, quase que exclusivamente, para aprovar ou reprovar, fazendo com que esse processo se torne excludente, uma vez que atribui ao aluno características de competente ou incompetente, ou seja, competente é aquele que consegue obter uma boa nota enquanto que, incompetente, seria aquele que obteve uma nota baixa.

Outro fator preponderante nessas práticas exclusivas é a atitude do docente no acolhimento do aluno que, muitas vezes não condiz com a necessidade da criança que chega à escola, desmotivando-a ao ponto de não querer mais estudar. Essa atitude é negativa, uma vez que o professor é a referência e responsável em promover a inserção do aluno, com todas as suas especificidades, no contexto educacional, promovendo assim, uma relação prazerosa e motivadora no ensino aprendizagem.

\section{A PRÁTICA DO LETRAMENTO: UMA PROPOSTA PARA A SALA DE AULA}

A evasão escolar nos dias atuais é um problema que assola as nossas escolas e preocupa o Estado porque impede, de certa forma, o avanço de nossa sociedade visto que, o desenvolvimento de uma nação está intimamente relacionado à educação. Diante dessa constatação torna-se necessária a busca por instrumentos que tornem a prática docente, como também o processo de ensino aprendizagem uma ferramenta no combate a esse mal.

RPI Revista de Pesquisa Interdisciplinar, Cajazeiras, v. 1, n. 1, 70-78, jan/jul. de 2016. 
Nesta perspectiva queremos apresentar a prática do letramento, como uma proposta que tem mostrado, ao longo dos anos, uma eficácia na prática pedagógica. De acordo com Magda Soares,

[...] Esse novo fenômeno só ganha visibilidade depois que é minimamente resolvido o problema do analfabetismo e que o desenvolvimento social, cultural, econômico e político traz novas, intensas e variadas práticas de leitura e de escrita, fazendo emergirem novas necessidades além de novas alternativas de lazer (SOARES, 1998, p.45-46).

Embora haja uma resistência, por parte de um grupo de docentes, uma vez que a mudança requer um maior empenho e dedicação no que se refere ao planejamento das aulas, essa prática já está sendo utilizada por muitos que têm constatado a sua importância no inserimento da criança em uma aprendizagem baseada na sua vivência social e cultural, ou seja, na sua totalidade.

Kleiman (2016) confirma esta concepção ao afirmar que não é tarefa fácil planejar este trabalho pedagógico. Isto porque, as salas de aulas são compostas por uma grande heterogeneidade, típico de um país continente como é considerado o nosso Brasil e que possui uma diversidade cultural, étnica, econômica, religiosa, etc, que deve dialogar juntos na construção de novos conhecimentos. Portanto, o conteúdo a ser trabalhado em sala de aula deve estar relacionado às práticas sociais do aluno. Isso significa uma mudança de mentalidade e um maior compromisso, para que se chegue a um denominador comum, que é o desenvolvimento integral da criança.

\section{UMA PROPOSTA DE ATIVIDADE}

Partimos da concepção de que na prática do letramento, busca-se fazer com que o aluno tenha uma nova relação com a leitura e a escrita, em que o mesmo possa, por meio destas, dar significado ao que está sendo apreendido por ele. Segundo kramer (1986):

A decisão sobre os métodos e as temáticas a serem utilizadas precisa levar em conta até que ponto eles favorecem essa compreensão, por parte das crianças, de que a palavra escrita significa algo, de que o código escrito não é um conhecimento livresco, abstrato, mas ao contrário, uma forma concreta de expressão e atendimento de objetos sentimentos e pensamentos reais. A escolha de como se ensina deve 
estar, então, subordinada à compreensão de como a criança aprende (p. 184).

Segue uma proposta de atividade baseada na prática do letramento com crianças que estejam no nível pré silábico para uma maior compreensão deste método.

Trabalhar o poema "As borboletas" de Vinícios de Morais

1. Expor um cartaz onde estará escrito o poema, bem como estarão representadas por meio de imagem colorida, todas as borboletas citadas no poema;

2. Fazer a leitura do poema quantas vezes se faça necessário para que as crianças associem o nome da cor com as respectivas borboletas, o som emitido pelas palavras ao serem pronunciadas, a pronúncia das palavras e etc.

3. Destacar uma palavra que será tida como PALAVRA CHAVE e a partir da mesma destacar:

- $\quad$ Letra inicial e final;

- $\quad$ Quantidade de letras;

- Quantidade de sílabas;

- Súlaba inicial.

4. Partindo da sílaba inicial, propor que cada aluno escreva à sua maneira o maior número de palavras que conseguir.

5. Expor as palavras que foram escritas em um mural para leitura coletiva com os alunos.

\section{CONSIDERAÇÕES FINAIS}

Através desta pesquisa foi possível constatar que, a evasão escolar é um fenômeno recorrente em nossa educação e que este, dentre outros fatores, pode ser causado por situações que envolvem o professor e o aluno. 
No caso do professor, um dos motivos que mais assolam seria a prática pedagógica, voltada na maioria das vezes para uma perspectiva tradicional, desconsiderando todos os conhecimentos prévios que a criança traz para a escola. Outro fator é o caso dos métodos avaliativos, ainda fortemente centrados na ideia de aprovação e reprovação, em que não há uma real preocupação em verificar se o aluno alcançou o objetivo da aprendizagem ou não. Além disso, entendemos que a capacidade de acolher as diversidades que o alunado possui, é uma virtude que muitos docentes precisam conquistar.

No que diz respeito ao aluno, não podemos desconsiderar o fator social, no que se refere ao meio em que ele está inserido, uma vez que a influência do seu ambiente implica num melhor ou pior desempenho escolar. Outro fator importante é a deficiência cognitiva e intelectual, que dificulta a sua inserção num contexto de interação em todo o processo ensino aprendizagem. Isso é causa de desmotivação e abandono escolar.

$\mathrm{Na}$ busca de possíveis respostas, que possam contribuir para uma menor evasão escolar, apresentamos a proposta do letramento, já que essa defende a importância de uma prática voltada para a vida social do aluno, em que a metodologia desenvolvida pelo docente não pode estar desvinculada do seu conhecimento empírico. Isso quer dizer que, deve haver um constante diálogo entre Escola, família e Sociedade com o intuito de formar verdadeiros cidadãos, capazes de atuar nas diferentes situações do seu cotidiano.

\section{REFERÊNCIAS}

ANGELUCCI et al. O estado da arte da pesquisa sobre o fracasso escolar. Educação e pesquisa, v.30, n.1, p. 51-72, jan./abr. 2004.

BRASIL. Lei de Diretrizes e Base Nacional. (LDBN). Brasília, DF, Senado, 1996.

GUIMARÃES, S. E. R.;BORUCHOVITCH, E. O estilo motivacional do professor e a motivação intrínseca dos estudantes: uma perspectiva da teoria da autodeterminação. Psicologia: reflexão e crítica, 17(2), pp.143-150, 2014.

KLEIMAN, A. B. O conceito de Letramento e suas implicações para a alfabetização. Disponível em: <http://www.letramento.iel.unicamp.br/publicacoes/artigos/Letramento_AngelaKleiman .pdf.>Acesso em 30 de ago 2016.

KRAMER, S. Alfabetização: dilemas da prática. Rio de Janeiro: ed. Dois Pontos, 1986. 
SOARES, M. Letramento - Um tema em Três Gêneros. Belo Horizonte: Autêntica, 1998.

VASCONCELLOS, C. S. A avaliação classificatória e excludente e a inversão fetichizada da função social. In: FERNANDES, C.O.(org.). Avaliação das aprendizagens: sua relação com o papel social da Escola. São Paulo: ed. Cortez, 2014. 